\title{
Psychometric Properties of the Photograph Series of Daily Activities-Short Electronic Version (PHODA-SeV) in Patients With Chronic Low Back Pain
}

Citation for published version (APA):

Oliveira, C. B., Franco, M. R., Demarchi, S. J., Smeets, R. J. E. M., Huijnen, I. P. J., Morelhao, P. K., Hisamatsu, T. M., \& Pinto, R. Z. (2018). Psychometric Properties of the Photograph Series of Daily Activities-Short Electronic Version (PHODA-SeV) in Patients With Chronic Low Back Pain. Journal of Orthopaedic \& Sports Physical Therapy, 48(9), 719-727. https://doi.org/10.2519/jospt.2018.7864

Document status and date:

Published: 01/09/2018

DOI:

10.2519/jospt.2018.7864

Document Version:

Publisher's PDF, also known as Version of record

Document license:

Taverne

Please check the document version of this publication:

- A submitted manuscript is the version of the article upon submission and before peer-review. There can be important differences between the submitted version and the official published version of record.

People interested in the research are advised to contact the author for the final version of the publication, or visit the DOI to the publisher's website.

- The final author version and the galley proof are versions of the publication after peer review.

- The final published version features the final layout of the paper including the volume, issue and page numbers.

Link to publication

\footnotetext{
General rights rights.

- You may freely distribute the URL identifying the publication in the public portal. please follow below link for the End User Agreement:

www.umlib.nl/taverne-license

Take down policy

If you believe that this document breaches copyright please contact us at:

repository@maastrichtuniversity.nl

providing details and we will investigate your claim.
}

Copyright and moral rights for the publications made accessible in the public portal are retained by the authors and/or other copyright owners and it is a condition of accessing publications that users recognise and abide by the legal requirements associated with these

- Users may download and print one copy of any publication from the public portal for the purpose of private study or research.

- You may not further distribute the material or use it for any profit-making activity or commercial gain

If the publication is distributed under the terms of Article 25fa of the Dutch Copyright Act, indicated by the "Taverne" license above, 


\author{
CRYSTIAN BITENCOURT OLIVEIRA, PT, MSC ${ }^{1}$ • MARCIA RODRIGUES FRANCO, PhD ${ }^{2}$ • SAMANTHA JANAINA DEMARCHI, PT ${ }^{1}$ \\ ROB JOHANNES E.M. SMEETS, PhD 3 ,4 • IVAN P.J. HUIJNEN, PhD ${ }^{3,5}$ • PRISCILA KALIL MORELHÃO, PT, MSC ${ }^{1}$ \\ THALYSI MAYUMI HISAMATSU, PT, MSc ${ }^{1}$ • RAFAEL ZAMBELLI PINTO, PhD ${ }^{6}$
}

\title{
Psychometric Properties of the Photograph Series of Daily Activities-Short Electronic Version (PHODA-SeV) in Patients With Chronic Low Back Pain
}

ow back pain (LBP) is a highly prevalent musculoskeletal condition and imposes a challenge for health care systems. ${ }^{10}$ Psychological factors are believed to contribute to the transition from acute to chronic pain and disability. ${ }^{27,41,42}$ The fear-avoidance

- BACKGROUND: The Photograph Series of Daily Activities-short electronic version (PHODA-SeV) assesses perceived harmfulness of daily activities in patients with low back pain (LBP). Although there is some evidence that the PHODA-SeV is a reliable and valid tool, its psychometric properties have not been fully investigated.

OBJECTIVES: To investigate the test-retest reliability, measurement error, interpretability, construct validity, and internal and external responsiveness of the PHODA-SeV in patients with chronic LBP.

METHODS: Ninety-one patients were included in the analysis for this prospective cohort study. For reliability purposes, the PHODA-SeV was administered twice, with a 1-week interval before beginning treatment. Pain, disability, and measures of pain-related fear (ie, PHODA-SeV, Fear-Avoidance Beliefs Questionnaire [FABQ], and Tampa Scale of Kinesiophobia [TSK]) were collected before and after the 8-week treatment period.

- RESULTS: The PHODA-SeV showed excellent reliability (intraclass correlation coefficient model $2,1=0.91$ ), without evidence of ceiling and floor ef- fects. The construct validity analysis demonstrated fair correlations $(r=0.25-0.50)$ of the PHODA-SeV with the FABQ, but no correlation with the TSK $(r<0.25)$. For internal responsiveness, the PHODASeV showed an effect size of 0.87 and a standardized response mean of 0.92 , interpreted as a large effect (greater than 0.80). For external responsiveness, the correlations between the PHODA-SeV and changes in the TSK and FABQ were considered low, and the receiver operating characteristic curve analyses revealed an area under the curve lower than the proposed threshold of 0.70 .

CONCLUSION: The PHODA-SeV is a reliable tool that can detect changes over time in pain-related fear in patients with chronic LBP undergoing physical therapy treatment. This tool, however, failed to identify those patients who did or did not improve, according to other pain-related fear measures. J Orthop Sports Phys Ther 2018;48(9):719-727. Epub 23 May 2018. doi:10.2519/jospt.2018.7864

KEY WORDS: chronic low back pain, painrelated fear, reliability, responsiveness, validity model postulates that factors, such as fear and expectation of adverse consequences from increasing activities, are associated with the development of avoidance behavior, resulting in disability, depression, and disuse. ${ }^{7,15,18,38}$ Pain-related fear, or the more specific fear that physical activities will cause injury or reinjury, is the central concept in the fear-avoidance model, which has been found to be associated with the maintenance of chronic $\mathrm{LBP}^{39}$ and with poor outcomes..$^{9,35}$ Hence, instruments with good psychometric properties that measure pain-related fear may help clinicians identify those patients with poor prognosis.

The Tampa Scale of Kinesiophobia (TSK) and the Fear-Avoidance Beliefs Questionnaire (FABQ) are commonly used tools to evaluate pain-related fear in patients with LBP. The TSK assesses the beliefs that a painful activity will cause damage, suffering, or functional loss. ${ }^{4}$ The FABQ was developed to measure levels of fear and avoidance beliefs about work and physical activity. ${ }^{40} \mathrm{Al}$ though both tools have demonstrated 
good psychometric properties, ${ }^{8,25,34}$ they fail to assess specific spinal movements or activities patients would fear or avoid in daily living. ${ }^{30}$

The Photograph Series of Daily Activities scale (PHODA) is an innovative tool ${ }^{14}$ that measures the extent to which patients with back pain regard movements or activities as harmful. The PHODA uses pictures to rate the harmfulness of a range of specific spinal movements and daily activities. Two versions of the PHODA are available: the original version, consisting of 100 photographs ${ }^{14}$ and the PHODA-short electronic version (PHODA-SeV), comprising 40 photographs. ${ }^{16}$ The PHODA$\mathrm{SeV}$ has the advantage of being easy to administer, which makes it suitable for routine use in clinical practice. Although the PHODA-SeV can be used to identify harmful activities that may be addressed using a specific intervention (eg, graded exposure), the tool may also be implemented as an evaluation measure after a full investigation of its psychometric properties.

Leeuw et al ${ }^{16}$ investigated the psychometric properties of the PHODA-SeV in adults with chronic LBP. The PHODA$\mathrm{SeV}$ showed good internal consistency, excellent reliability, and consistent relationships with related constructs, such as self-report measures of fear of movement/injury/reinjury, pain catastrophizing, functional disability, and current pain intensity. However, the previous study selected its participants from a previous trial of participants with high levels of fear of movement who were referred by physicians in the Netherlands. Given that not all measurement properties have been evaluated and to increase the implementation of this instrument to measure pain-related fear, the aim of this study was to fully investigate the measurement properties of the PHODA$\mathrm{SeV}$, including internal consistency, reliability, measurement error, construct validity, responsiveness, and interpretability, in patients with nonspecific chronic LBP.

\section{METHODS}

$\mathbf{T}$ E PROTOCOL FOR THIS PROSPECtive cohort study was previously registered with ClinicalTrials.gov (NCT02398760).

\section{Participants}

Patients with nonspecific chronic LBP were recruited through local press and social media advertisements, and from 2 outpatient physical therapy university clinics in Presidente Prudente, Brazil. To be included, patients had to be between 18 and 60 years of age and diagnosed with nonspecific chronic LBP (defined as pain for at least 3 months in duration that is not attributable to a specific cause below the costal margin and above the inferior gluteal folds, with or without leg pain). In addition, patients had to report LBP of at least moderate intensity (ie, at least 4 points on a 0 -to-10 numeric pain-rating scale [NPRS]) or moderate interference with function as measured by items 7 and 8 of the Medical Outcomes Study 36Item Short-Form Health Survey. ${ }^{5}$

Patients were excluded if they presented with suspected or diagnosed serious spinal pathology (eg, inflammatory spondyloarthropathy, fracture, malignancy, cauda equina syndrome, or infection); nerve root compromise (indicated by at least 2 of the following: weakness, reflex change, or sensation loss associated with the same spinal nerve); history of spinal surgery, fibromyalgia, or any other musculoskeletal condition that may affect activity and movement; pregnancy; illiteracy; insufficient understanding of the Portuguese language; or any contraindication to exercise, according to the American College of Sports Medicine. ${ }^{2}$

Initial examination was performed by a physical therapist. The Research Ethics Committee at São Paulo State University approved the study (CAAE36332514.0.0000.5402), and all participants provided informed consent.

\section{Procedures}

For those patients considered eligible, the authors collected sociodemographic and anthropometric data, symptom duration, pain intensity, disability, and measures of pain-related fear (ie, the PHODA-SeV, TSK, and FABQ). The questionnaires were administered by 2 trained assessors, but the order of administration was not randomized. For reliability purposes, the PHODA-SeV was administered again 1 week after the initial assessment, before the start of treatment. This time interval was adopted to prevent recall of the previous assessment and to ensure that the patient's condition remained unchanged.

After initial assessments, all included participants underwent an individual program delivered by physical therapists, twice a week for 8 weeks. The intervention did not have a protocol, but the physical therapists who administered the treatment were instructed to follow the clinical practice guidelines for the management of chronic LBP (ie, supervised exercise therapy). ${ }^{13}$ Pain intensity, disability, and measures of pain-related fear were collected following the 8-week treatment period (ie, 9 weeks after the initial assessment).

\section{Instruments}

A standardized assessment form was used to collect demographic and anthropometric data (eg, age, sex, body mass index, employment status [unemployed or employed]), duration of symptoms, pain intensity, disability, level of painrelated fear, and perception of recovery (only post intervention). The Brazilian Portuguese versions or adaptations of the questionnaires were used in the present study. The NPRS was used to assess the average pain intensity during the last 24 hours. The NPRS ranges from 0 ("no pain") to 10 ("worst pain possible"). The Roland-Morris Disability Questionnaire was used to measure disability. ${ }^{26,31}$ The Roland-Morris Disability Questionnaire consists of 24 yes-or-no items, with a total score ranging from 0 ("no disability") to 24 ("maximum disability"). 
Measures of pain-related fear assessed in this study were the FABQ, TSK, and PHODA-SeV. The FABQ is a self-reported questionnaire consisting of 16 items grouped in 2 subscales: physical activity and work. Of these, 11 items (7 items from the work subscale and 4 items from the physical activity subscale) are scored from 0 ("totally disagree") to 6 points ("totally agree").,140 The FABQ has a total score ranging from 0 to 66 points, with higher scores indicating higher fearavoidance beliefs. The Brazilian Portuguese version of the FABQ has shown good reliability (intraclass correlation coefficient $[\mathrm{ICC}]_{2,1}=0.96 ; 95 \%$ confidence interval [CI]: 0.94, 0.98). ${ }^{8}$

The TSK is a self-reported questionnaire consisting of 17 items. Each item is ranked on a scale from 1 ("totally disagree") to 4 points ("totally agree"). ${ }^{22,32}$ The TSK total scores range from 17 to 68 points, with higher scores indicating greater levels of fear of movement. The Brazilian Portuguese version of the TSK demonstrated high reliability $\left(\mathrm{ICC}_{2,1}=\right.$ 0.93; $95 \% \mathrm{CI}: 0.87,0.96){ }^{8}$

The PHODA-SeV is a self-administered tool used to assess the perceived harmfulness of movements performed during daily activities. This tool uses pictures to describe 8 possible movements (lifting, bending, turning, reaching, falling, intermittent load-unexpected movement, and long-lasting load in stance or sitting with limited dynamics), set against 4 areas of daily occupations (activities of daily living, housekeeping, work and sports, and leisure time) and converted into recognizable and frequent daily activities rather than in terms of their biomechanics. ${ }^{16}$ The original version of the PHODA included 100 photographs of daily activities. ${ }^{14}$ The current study used a shortened electronic version of the $\mathrm{PHO}-$ DA, the PHODA-SeV, which contains 40 selected photographs. ${ }^{16}$ Because the PHODA-SeV is an electronic instrument, each patient was shown how to score the items using a laptop computer.

Participants rated the activities using a scale ranging from $\mathrm{O}$ ("not harmful at all") to 100 ("extremely harmful"). They were asked to look at the photographs and try to imagine themselves performing each activity depicted. Then, for each photograph, participants answered the following question: "How harmful do you feel that this activity would be for your back?" A total score was calculated by averaging the score of each of the 40 photographs.

\section{Statistical Analysis}

Data are presented as frequency (proportion), mean $\pm \mathrm{SD}$, and median (interquartile range). The paired $t$ test was used to compare the differences between baseline and 8-week follow-up. The present study also assessed the following measurement properties of the PHODA-SeV.

Internal Consistency Internal consistency investigates the level of interrelatedness between the items of the instrument. Cronbach's alpha was calculated to analyze the internal consistency of the PHODA-SeV, with values ranging from .70 to .95 indicating sufficient homogeneity. ${ }^{36}$

Test-Retest Reliability Test-retest reliability is the extent to which the measures for the same patients remain unchanged after repeated measurements. The ICC (model 2,1) was used to calculate intrarater reliability, using the total score and scores for each item of the PHODA-SeV; ICC values greater than 0.70 indicate excellent reliability. ${ }^{36}$

Measurement Error Measurement error is the error of a patient's score that is not attributable to true changes in the construct measured. The standard error of measurement (SEM) and smallest detectable change (SDC) were calculated using the following formulas: $S E M=S D \times \sqrt{1-I C C}$ and $S D C=1.96 \times \sqrt{2} \times S E M$, where SD is the standard deviation of the baseline. The SEM reflects the possibility that the change in the measure may be attributable to random error. The SDC is defined as the smallest within-person change in the measure that can be interpreted as a real change, above the measurement error. $^{36}$

Construct Validity The construct validity measures the degree to which the instru- ment is consistent with the hypotheses, based on the assumption that the instrument validly measures the construct it is intended to measure. The Pearson correlation coefficient $(r)$ was used to analyze the correlations of the PHODA-SeV with other measures of pain-related fear (ie, TSK and FABQ). The levels of construct validity are interpreted as follows: weak validity, $r<0.30$; moderate validity, $r=$ $0.30-0.60$; good validity, $r>0.60 .{ }^{36}$ The authors' hypothesis for construct validity was that the PHODA-SeV would show positive and at least moderate validity with at least 1 measure of pain-related fear (the TSK or FABQ).

Responsiveness There are 2 major aspects of responsiveness: internal and external. Internal responsiveness refers to the ability of a measure to change over a prespecified time frame, and external responsiveness reflects the extent to which change in a measure relates to a corresponding change in a reference measure of clinical or health status. ${ }^{11}$ Internal responsiveness was calculated as effect size (mean change/SD of baseline) and standardized response mean (SRM) (mean change/SD of change), where mean change was calculated as the difference between baseline and posttreatment scores.

Considering that the TSK and FABQ also assess pain-related fear constructs, the researchers divided the sample into "improved" and "not improved," using the changes in TSK and FABQ scores as external anchors to investigate external responsiveness. For the TSK, patients with change scores equal to or more than 12 points were categorized as "improved" and patients with scores of less than 12 points were considered "not improved." For the FABQ, patients with change scores equal to or more than 17 points were categorized as "improved" and patients scoring less than 17 were categorized as "not improved." The cutoff points for the TSK and FABQ were determined using the SDC. The authors calculated the SDC using the ICC reported in previous studies investigating the psychometric properties of these questionnaires. ${ }^{1,32}$ 
The effect size and SRM were interpreted as follows: 0.20 represented a small effect, 0.50 a moderate effect, and 0.80 a large effect. ${ }^{6}$ For external responsiveness, the researchers correlated the change in the PHODA-SeV (baseline minus follow-up score) with change scores of the TSK and FABQ and conducted the receiver operating characteristic (ROC) analysis. If the ROC analysis showed an area under the curve (AUC) equal to or greater than 0.70 , then the instrument was considered to have appropriate external responsiveness. An AUC of 0.70 means that the instrument can correctly identify the participant's condition ("improved" or "not improved") in $70 \%$ of the sample.

According to the COnsensus-based Standards for the selection of health Measurement INstruments (COSMIN) checklist, ${ }^{24}$ the responsiveness must be examined using a priori-formulated hypotheses. The criterion used to assess the responsiveness is that the results should be in accordance with at least $75 \%$ of the hypotheses. ${ }^{23}$ Previous studies showed the performance of pain-related fear measures to vary from low to medium effect sizes (less than 0.5) after a physical therapy treatment, ${ }^{8,33}$ and from medium to large effect sizes (greater than 0.5) after multidisciplinary treatment. ${ }^{3,17,25}$ Hence, for internal responsiveness, this study's hypotheses were that the effect size and SRM of the PHODA-SeV would be at least 0.5 (hypotheses 1 and 2). Considering the changes in TSK and FABQ scores, the authors also hypothesized that the effect size and SRM for those patients categorized as "improved" would be large (ie, greater than 0.80) (hypothesis 3), and for those categorized as "not improved" would be at least medium (ie, greater than 0.50) (hypothesis 4). The authors considered the PHODA-SeV to have appropriate internal responsiveness if at least 3 of the 4 hypotheses ( $75 \%$ ) were supported.

For external responsiveness, given that a previous study found a moderate correlation $(r=0.37)$ between the
TSK and PHODA-SeV, ${ }^{16}$ the researchers hypothesized that the change in PHODA-SeV score would show at least moderate correlations with the change scores of the TSK (hypothesis 1) or FABQ (hypothesis 2). The magnitude of the Pearson correlation coefficient was interpreted as 0.00 to 0.25 , little or no correlation; 0.25 to 0.50 , fair correlation; 0.50 to 0.75 , moderate to good correlation; and greater than 0.75 , excellent correlation..$^{29}$ They also hypothesized that AUCs, using the TSK (hypothesis 3) and FABQ (hypothesis 4) as external anchors, would be equal to or greater than 0.70 . The authors considered the PHODA-SeV to have appropriate external responsiveness if at least 3 of the 4 hypotheses ( $75 \%$ ) were supported.

Interpretability Interpretability is the degree to which one can ascribe a qualitative meaning to quantitative scores. For interpretability, the authors calculated the floor and ceiling effects and the change scores for pain, disability, and measures of pain-related fear. Floor and ceiling effects were calculated through the percentage of participants who achieved the maximum score (ceiling effect) or the minimum score (floor effect) of the questionnaire. Ceiling and floor effects were considered present when more than $15 \%$ of the participants achieved the maximum or minimum score, respectively. ${ }^{36}$

All statistical analyses were performed using SPSS Version 20.0 (IBM Corporation, Armonk, NY).

\section{RESULTS}

rom August 2014 to December 2015, 104 patients with nonspecific chronic LBP were recruited. Patients who did not complete the 8-week treatment were excluded from the analysis. A total of 91 patients finished the 8-week treatment and were included. No missing items were identified in the questionnaires from those patients included in the analyses. More than two thirds $(\mathrm{n}=62)$ of the sample were women, and the entire sample had a mean \pm SD age of 37.8 \pm 12.4 years and a median duration of pain of 18 months (interquartile range, 6.0-48.0 months). TABLE 1 describes the sample's characteristics.

\section{Internal Consistency, Test-Retest Reliability, and Measurement Error}

Cronbach's alpha of the total score for the PHODA-SeV was .95, indicating homogeneity among the items of the instrument. The total scores of the PHODA-SeV demonstrated an $\mathrm{ICC}_{2,1}$ of 0.91 (95\% CI: 0.86 , 0.94), indicating excellent reliability. The SEM and SDC were 5.46 and 15.13 points on a scale from 0 to 100 , respectively. The reliability of each activity of the PHODA$\mathrm{SeV}$ ranged from 0.56 (ie, ironing while sitting and lifting pot with bent back) to 0.86 (ie, walking up stairs), indicating good to excellent reliability. TABLE 2 describes the reliability for each item of the PHODA-SeV.

\section{Construct Validity}

TABLE 3 shows the construct validity results. This study's findings suggest mod-

\begin{tabular}{|l|c|}
\hline \multicolumn{1}{|c|}{ TABLE 1} & SAMP LE CHARACTER ISTICS* \\
\hline Characteristic & Sample $(\mathbf{n}=91)$ \\
\hline Age, $\mathrm{y}$ & $37.8 \pm 12.4$ \\
Sex (female), $\mathrm{n}(\%)$ & $62(68)$ \\
Body mass index, $\mathrm{kg} / \mathrm{m}^{2}$ & $26.4 \pm 5.2$ \\
Duration of pain, $\mathrm{mo}^{\dagger}$ & $18.0(6.0-48.0)$ \\
Not employed, $\mathrm{n}(\%)$ & $37(41)$ \\
\hline${ }^{*}$ Values are mean \pm SD unless otherrise indicated. \\
${ }^{+}$Values are median (interquartile range). \\
\hline
\end{tabular}


erate validity for the PHODA-SeV, as there was a fair correlation with 1 measure of pain-related fear (ie, the FABQ).

\section{Responsiveness}

TABLE 4 shows the findings for the responsiveness analyses. For internal responsiveness, a large effect size and large SRM were found for the whole sample and for the subgroups of patients categorized as "improved" and "not improved." The only exception found was for the effect size of the "improved" subgroup defined according to the change in TSK score, which showed a medium effect size. All 4 a priori-formulated hypotheses related to internal responsiveness were supported.

For external responsiveness, the authors found a low correlation between the changes in TSK and FABQ score and change on the PHODA-SeV. In addition, the ROC curve analysis considering the patients who were "improved" and "not improved" on the TSK and FABQ showed an AUC lower than the cutoff point of 0.70. None of the a priori-formulated hypotheses related to external responsiveness were supported.

\section{Interpretability}

Floor effects and ceiling effects were not detected for the PHODA-SeV. None of the participants reported the highest or lowest score. Furthermore, TABLE 5 presents the comparison before and after the 8-week treatment for all measures.

\section{DISCUSSION}

\section{$\mathrm{T}$} HESE FINDINGS REVEALED THAT THE PHODA-SeV is a reliable tool to assess pain-related fear in patients undergoing physical therapy treatment. Furthermore, this study supported all a priori-formulated hypotheses related to internal responsiveness, suggesting that this instrument can detect change after an 8 -week physical therapy treatment. The PHODA-SeV also showed fair construct validity and poor external responsiveness. Based on these results, the authors recommend the PHODA-SeV as a reliable

\begin{tabular}{|c|c|c|c|}
\hline \multirow{2}{*}{$\begin{array}{l}\text { TABLE } 2 \\
\text { Item }\end{array}$} & \multicolumn{3}{|c|}{$\begin{array}{l}\text { Mean Values (First and Second } \\
\text { Assessments) and Reliability } \\
\text { of Each Item of the PHODA-SeV* }\end{array}$} \\
\hline & First Assessment & Second Assessment & $\operatorname{ICC}^{\dagger}$ \\
\hline Shoveling soil & $84.3 \pm 17.8$ & $83.1 \pm 20.4$ & $0.70(0.57,0.79)$ \\
\hline Falling backward & $83.7 \pm 23.0$ & $80.1 \pm 25.3$ & $0.78(0.69,0.85)$ \\
\hline Lifting pot, bent back & $76.2 \pm 22.4$ & $78.0 \pm 20.7$ & $0.56(0.41,0.69)$ \\
\hline Carrying child on hip & $74.6 \pm 22.9$ & $76.0 \pm 24.3$ & $0.59(0.44,0.71)$ \\
\hline Vacuum cleaning & $74.5 \pm 23.9$ & $73.4 \pm 22.3$ & $0.58(0.42,0.70)$ \\
\hline Mopping floor & $72.7 \pm 27.2$ & $72.0 \pm 23.4$ & $0.70(0.58,0.79)$ \\
\hline Lifting beer crate, bent back & $72.6 \pm 26.3$ & $73.5 \pm 22.0$ & $0.75(0.65,0.83)$ \\
\hline Lifting basket, walking up stairs & $70.3 \pm 24.9$ & $70.2 \pm 24.3$ & $0.68(0.55,0.78)$ \\
\hline Picking up shoes, bent back & $70.2 \pm 24.6$ & $65.5 \pm 24.8$ & $0.58(0.42,0.70)$ \\
\hline Lifting toddler from cot & $64.4 \pm 26.1$ & $68.2 \pm 24.1$ & $0.72(0.61,0.81)$ \\
\hline Mowing lawn & $64.0 \pm 27.9$ & $67.3 \pm 26.0$ & $0.68(0.55,0.78)$ \\
\hline Drilling hole above head & $61.9 \pm 26.8$ & $61.3 \pm 27.1$ & $0.78(0.68,0.84)$ \\
\hline Carrying 2 shopping bags, both hands & $61.5 \pm 29.8$ & $60.6 \pm 26.4$ & $0.68(0.55,0.78)$ \\
\hline Carrying rubbish bag, 1 hand & $59.7 \pm 28.0$ & $58.0 \pm 25.7$ & $0.60(0.45,0.71)$ \\
\hline Carrying shopping bag, 1 hand & $59.3 \pm 28.6$ & $60.2 \pm 25.3$ & $0.58(0.43,0.70)$ \\
\hline Lifting pot, squatting & $57.5 \pm 28.9$ & $62.7 \pm 27.4$ & $0.63(0.49,0.74)$ \\
\hline Running through forest & $57.0 \pm 32.1$ & $52.8 \pm 32.8$ & $0.71(0.59,0.80)$ \\
\hline Back bending & $56.9 \pm 29.8$ & $58.5 \pm 30.3$ & $0.67(0.54,0.77)$ \\
\hline Taking heavy box from shelf above head & $56.8 \pm 27.4$ & $61.4 \pm 27.0$ & $0.66(0.53,0.76)$ \\
\hline Picking up shoes, squatting & $55.8 \pm 27.8$ & $53.6 \pm 27.1$ & $0.64(0.50,0.74)$ \\
\hline Making bed & $55.4 \pm 29.2$ & $57.1 \pm 28.7$ & $0.80(0.71,0.86)$ \\
\hline Clearing out dishwasher & $55.0 \pm 27.0$ & $56.1 \pm 27.2$ & $0.65(0.51,0.75)$ \\
\hline Ironing while standing & $54.5 \pm 29.2$ & $60.1 \pm 26.8$ & $0.62(0.48,0.74)$ \\
\hline Rope skipping & $54.1 \pm 32.0$ & $53.8 \pm 33.2$ & $0.83(0.75,0.88)$ \\
\hline Riding bike on bumpy street & $53.5 \pm 31.2$ & $55.7 \pm 29.9$ & $0.63(0.49,0.74)$ \\
\hline Trampoline jumping & $53.4 \pm 31.0$ & $51.4 \pm 32.6$ & $0.75(0.65,0.83)$ \\
\hline Abdominal exercises & $52.4 \pm 30.4$ & $54.0 \pm 29.2$ & $0.74(0.62,0.82)$ \\
\hline Cleaning windows above head & $51.1 \pm 28.6$ & $52.6 \pm 28.7$ & $0.69(0.57,0.79)$ \\
\hline Back twisting & $50.4 \pm 30.7$ & $53.1 \pm 28.1$ & $0.69(0.57,0.78)$ \\
\hline Cycling from curb & $50.4 \pm 28.2$ & $53.4 \pm 28.7$ & $0.72(0.60,0.81)$ \\
\hline Taking box from cupboard & $50.3 \pm 30.8$ & $49.1 \pm 28.8$ & $0.80(0.72,0.87)$ \\
\hline Doing dishes & $50.2 \pm 26.7$ & $52.5 \pm 25.1$ & $0.59(0.43,0.71)$ \\
\hline Leg stretching & $48.6 \pm 31.7$ & $54.4 \pm 28.8$ & $0.68(0.56,0.78)$ \\
\hline Taking book, twisted back & $47.4 \pm 28.9$ & $46.9 \pm 27.9$ & $0.64(0.51,0.75)$ \\
\hline Cycling, looking aside & $43.4 \pm 31.5$ & $44.7 \pm 30.4$ & $0.79(0.70,0.86)$ \\
\hline Getting out of bed & $41.4 \pm 39.3$ & $42.2 \pm 30.2$ & $0.62(0.48,0.73)$ \\
\hline Ironing while sitting & $41.3 \pm 28.5$ & $44.8 \pm 26.2$ & $0.56(0.41,0.69)$ \\
\hline Walking up stairs & $40.2 \pm 28.7$ & $41.1 \pm 29.9$ & $0.86(0.79,0.90)$ \\
\hline Walking through forest & $37.3 \pm 29.8$ & $36.0 \pm 27.2$ & $0.73(0.61,0.81)$ \\
\hline Walking down stairs & $35.2 \pm 28.9$ & $36.1 \pm 29.1$ & $0.83(0.76,0.89)$ \\
\hline
\end{tabular}




\section{[ RESEARCH REPORT ]}

tool to evaluate pain-related fear and detect change over time in patients with chronic LBP in primary care settings.

The PHODA-SeV demonstrated consistent and reproducible results and

\begin{tabular}{|c|c|c|c|}
\hline TABLE 3 & \multicolumn{3}{|c|}{ Pearson Correlation Coefficients* } \\
\hline Measurement & FABQ & TSK & PHODA-SeV \\
\hline FABQ & 1 & & \\
\hline TSK & $0.46^{\dagger}$ & 1 & \\
\hline PHODA-SeV & $0.39+$ & $0.22^{\ddagger}$ & 1 \\
\hline \multicolumn{4}{|c|}{$\begin{array}{l}\text { Abbreviations: FABQ, Fear-Avoidance Beliefs Questionnaire; } P H O D A-S e V, \text { Photograph Series of Dail. } \\
\text { Activities-short electronic version; TSK, Tampa Scale of Kinesiophobia. } \\
{ }^{*} \text { Data used in the analyses were collected at baseline. } \\
{ }^{+} P<.01 \text {. } \\
{ }^{+} P<.05 \text {. }\end{array}$} \\
\hline
\end{tabular}

\begin{tabular}{|c|c|c|c|c|}
\hline \multicolumn{5}{|c|}{ Responsiveness Analysis of the PHODA-SeV } \\
\hline Measurement & n & Changes in the TSK & n & Changes in the FABQ \\
\hline Total sample & 91 & & 91 & \\
\hline Effect size & & 0.87 & & 0.87 \\
\hline Standardized response mean & & 0.92 & & 0.92 \\
\hline Improved & 13 & & 29 & \\
\hline Effect size & & 0.79 & & 1.07 \\
\hline Standardized response mean & & 0.85 & & 1.01 \\
\hline Not improved & 78 & & 62 & \\
\hline Effect size & & 0.90 & & 0.85 \\
\hline Standardized response mean & & 0.92 & & 0.87 \\
\hline Correlation with changes in the PHODA-SeV & & 0.08 & & 0.12 \\
\hline Area under the curve* & & $0.49(0.34,0.65)$ & & $0.43(0.30,0.56)$ \\
\hline $\begin{array}{l}\text { Abbreviations: FABQ, Fear-Avoidance } \\
\text { Activities-short electronic version; } T \text { TSK } \\
{ }^{*} \text { Values in parentheses are } 95 \% \text { confide }\end{array}$ & $f$ & $\begin{array}{l}\text { ionnaire; } P H O D A- \\
\text { e of Kinesiophobia. }\end{array}$ & Phot & raph Series of Daily \\
\hline
\end{tabular}

$\mathrm{SeV}$ in adults ${ }^{16}$ and adolescents, ${ }^{37}$ which also found high reliability as well as correlation with a pain-related fear measure.

Regarding the construct validity of the PHODA-SeV, the present study investigated which construct of pain-related fear would be correlated with the instrument. The results revealed that the PHODA-SeV showed moderate validity with the FABQ $(r=0.39, P<.01)$ but weak validity with the TSK $(r=0.22$, $P<.05)$. By contrast, Leeuw et $\mathrm{al}^{16}$ found that the PHODA-SeV had a higher correlation with the TSK $(r=0.37, P<.01)$ in a sample of patients with scores higher than 33 points for that questionnaire. The authors believe that the differences between the samples used in both studies may have contributed to these inconsistencies in the strength of correlations.

In addition, the present study's results showed that, on average, patients scored 16 points (95\% CI: $-12.4,-19.6)$ lower on the PHODA-SeV after a course of physical therapy treatment. This change was greater than the measurement error (SDC, 15.13 points), suggesting that real change might have occurred in terms of pain-related fear in this sample.

This is the first study to investigate the internal and external responsiveness of the PHODA-SeV after physical therapy treatment in patients with chronic LBP. The COSMIN checklist recommends that hypotheses should be formulated a priori, and that the instrument is considered to have appropriate responsiveness when $75 \%$ of these a

\begin{tabular}{|c|c|c|c|c|}
\hline TABLE 5 & \multicolumn{4}{|c|}{ Baseline, Follow-up, and Change Means of the Instruments* } \\
\hline Measurement & Baseline & 8-wk Follow-up & Mean Change & $P$ Value \\
\hline NPRS & $6.5 \pm 1.7(2-10)$ & $2.6 \pm 2.3(0-8)$ & -3.9 (95\% Cl: $-4.5,-3.3 ;$ range, -9 to 3 ) & $<.01$ \\
\hline RMDQ & $11.7 \pm 4.7(3-24)$ & $3.6 \pm 4.2(0-18)$ & -8.1 (95\% Cl: $-9.4,-6.9$; range, -24 to 9$)$ & $<.01$ \\
\hline FABQ & $34.8 \pm 13.3(7-64)$ & $24.5 \pm 14.9(0-59)$ & -10.3 (95\% Cl: $-13.5,-7.0 ;$; range, -49 to 23 ) & $<.01$ \\
\hline TSK & $40.8 \pm 6.9(25-59)$ & $36.8 \pm 6.7(23-58)$ & -4.0 (95\% Cl: $-5.8,-2.2 ;$ range, -25 to 21$)$ & $<.01$ \\
\hline PHODA-SeV & $57.5 \pm 18.2(10.2-97.0)$ & $41.4 \pm 21.2(2.5-86.0)$ & -16.0 (95\% Cl: $-19.6,-12.4$; range, -74.0 to 14.2$)$ & $<.01$ \\
\hline
\end{tabular}


priori-formulated hypotheses are supported..$^{36}$ These findings revealed that all 4 a priori-formulated hypotheses were supported, indicating appropriate internal responsiveness for the PHODA-SeV.

Regarding the ability of the PHODA$\mathrm{SeV}$ to detect change after a course of physical therapy treatment, this study revealed a large effect size (0.87). The data derived from a previous randomized controlled trial ${ }^{17}$ in a population with chronic LBP showed an even larger effect size (1.53) than that calculated in the present study. The larger effect size found in Leeuw et a ${ }^{17}$ may be due to the use of an intervention, in half of the sample, with a specific focus on reducing pain-related fear (ie, exposure in vivo). Previous studies, however, showed that physical therapy is also effective in reducing painrelated fear in patients with LBP. ${ }^{20,21}$ The large effect size (greater than 0.80) found in the current study suggests that the PHODA-SeV may also be able to detect change over time in patients receiving supervised exercise therapy.

Regarding the external responsiveness analysis, the correlations between the change in PHODA-SeV score and the changes in TSK and FABQ score were found to be low, and the AUC was below the proposed threshold (AUC lower than 0.70). These findings suggest that the PHODA-SeV may not be suitable to distinguish patients who did or did not improve their TSK and FABQ scores after a course of physical therapy treatment. Further studies should investigate external responsiveness using other pain-related fear measures as external anchors in the analyses.

This study revealed that the PHODA-SeV has similar, or even better, psychometric properties compared to the most commonly used questionnaires to assess pain-related fear (ie, the TSK and FABQ). Like this study, previous research also found high reliability and did not detect ceiling and floor effects for the TSK and FABQ. ${ }^{8}$

The results of the present study revealed a higher effect size for the PHODA-
$\mathrm{SeV}$ compared to the results of a previous study examining the TSK and FABQ, ${ }^{8}$ suggesting that the PHODA-SeV may be the preferable questionnaire to detect changes in the pain-related fear construct after a course of physical therapy treatment. Nevertheless, this study revealed poor external responsiveness for the PHODA-SeV. Indeed, the authors identified 2 studies $^{8,25}$ investigating the external responsiveness of the TSK and FABQ. These studies, however, used patient perception of recovery as an external anchor, which may not be considered an adequate comparison with this study's results or the most appropriate criterion for investigating external responsiveness. This is because patient perception of recovery does not measure the construct of pain-related fear.

The current study has some limitations that should be considered in the interpretation of these findings. Like the study of Leeuw et al,${ }^{16}$ the authors used self-report measures (ie, the TSK and FABQ) to investigate the construct validity of the PHODA-SeV. Future studies should consider the use of behavioral task performance to explore the related constructs. ${ }^{4,12,19,28,43}$

The lack of sample-size calculation to obtain an optimal number of participants should also be considered a limitation. Nevertheless, this study would be rated as having good methodological quality (ie, more than 50 but fewer than 100 participants) according to the COSMIN benchmarks.

Another potential limitation is that the questionnaires were not administered in a random order. Hence, it is not possible to rule out bias due to test-order effects.

Furthermore, the administration of the PHODA-SeV may be considered time consuming, which may be viewed as a barrier to wide use of this tool in clinical practice. Given that the PHODA-SeV was developed for the Dutch population, it is also possible that some photographs do not depict common activities performed by the Brazilian population. While the patients recruited for this study reported no difficulties with any of the items or activities, further research is still needed to ex- plore whether the activities depicted in the PHODA-SeV remain relevant, depending on the sociodemographic and geographical contexts in which they are performed.

Still another limitation is that these results can only be generalized to patients with chronic LBP. Future studies of patients with acute LBP are still needed.

\section{CONCLUSION}

$\mathbf{T}$ He PHODA-SeV proved to Be A reliable instrument, able to detect changes over time in pain-related fear in patients with chronic LBP undergoing physical therapy treatment. This study showed that the PHODA$\mathrm{SeV}$ is not able to identify those patients who improved or did not improve their TSK and FABQ scores after a course of physical therapy treatment. Future studies are still warranted that will investigate the responsiveness of the PHODA-SeV after, for instance, a treatment approach designed specifically to reduce pain-related fear. 0

\section{KEY POINTS}

FINDINGS: This study provides evidence that the Photograph Series of Daily Activities-short electronic version (PHO$\mathrm{DA}-\mathrm{SeV}$ ) is a reliable tool able to detect change over time in pain-related fear in patients with chronic low back pain. IMPLICATIONS: The PHODA-SeV may be used to evaluate pain-related fear in primary care settings.

CAUTION: The administration of the PHODA-SeV may be considered time consuming and can only be generalized to patients with chronic low back pain.

\section{REFERENCES}

1. Abreu AM, Faria CD, Cardoso SM, TeixeiraSalmela LF. [The Brazilian version of the Fear Avoidance Beliefs Questionnaire]. Cad Saúde Pública. 2008;24:615-623. https://doi. org/10.1590/S0102-311X2008000300015

2. American College of Sports Medicine. ACSM's Guidelines for Exercise Testing and Prescription. 9th ed. Baltimore, MD: Wolters Kluwer Health/ 
Lippincott Williams \& Wilkins; 2014.

3. Brox JI, Nygaard ØP, Holm I, Keller A, Ingebrigtsen T, Reikerås 0 . Four-year follow-up of surgical versus non-surgical therapy for chronic low back pain. Ann Rheum Dis. 2010;69:16431648. https://doi.org/10.1136/ard.2009.108902

4. Bunzli S, Smith A, Watkins R, Schütze R, O'Sullivan P. What do people who score highly on the Tampa Scale of Kinesiophobia really believe? A mixed methods investigation in people with chronic nonspecific low back pain. Clin JPain. 2015;31:621-632. https://doi.org/10.1097/ AJP.0000000000000143

5. Ciconelli RM, Ferraz MB, Santos W, Meinão I, Quaresma MR. [Brazilian-Portuguese version of the SF-36. A reliable and valid quality of life outcome measure]. Rev Bras Reumatol. 1999:39:143-150.

6. Cohen J. Statistical Power Analysis for the Behavioral Sciences. 2nd ed. Hillsdale, NJ: Lawrence Erlbaum Associates; 1988.

7. den Hollander M, de Jong JR, Volders S, Goossens ME, Smeets RJ, Vlaeyen JW. Fear reduction in patients with chronic pain: a learning theory perspective. Expert Rev Neurother. 2010;10:17331745. https://doi.org/10.1586/ern.10.115

8. de Souza FS, da Silva Marinho C, Siqueira FB, Maher CG, Costa LO. Psychometric testing confirms that the Brazilian-Portuguese adaptations, the original versions of the FearAvoidance Beliefs Questionnaire, and the Tampa Scale of Kinesiophobia have similar measurement properties. Spine (Phila Pa 1976). 2008;33:1028-1033. https://doi.org/10.1097/ BRS.0b013e31816c8329

9. George SZ, Fritz JM, Childs JD. Investigation of elevated fear-avoidance beliefs for patients with low back pain: a secondary analysis involving patients enrolled in physical therapy clinical trials. J Orthop Sports Phys Ther. 2008;38:5058. https://doi.org/10.2519/jospt.2008.2647

10. Hoy D, March L, Brooks P, et al. The global burden of low back pain: estimates from the Global Burden of Disease 2010 study. Ann Rheum Dis. 2014;73:968-974. https://doi. org/10.1136/annrheumdis-2013-204428

11. Husted JA, Cook RJ, Farewell VT, Gladman DD. Methods for assessing responsiveness: a critical review and recommendations. J Clin Epidemiol. 2000;53:459-468. https://doi.org/10.1016/ S0895-4356(99)00206-1

12. Karayannis NV, Smeets RJ, van den Hoorn W, Hodges PW. Fear of movement is related to trunk stiffness in low back pain. PLoS One. 2013;8:e67779. https://doi.org/10.1371/journal. pone. 0067779

13. Koes BW, van Tulder M, Lin CW, Macedo LG, McAuley J, Maher C. An updated overview of clinical guidelines for the management of nonspecific low back pain in primary care. Eur Spine J. 2010;19:2075-2094. https://doi.org/10.1007/ s00586-010-1502-y

14. Kugler K, Wijn J, Geilen M, de Jong J, Vlaeyen JW. The Photograph Series of Daily Activities
(PHODA). Hoensbroeck, the Netherlands: Institute for Rehabilitation Research; 1999.

15. Leeuw M, Goossens ME, Linton SJ, Crombez G, Boersma K, Vlaeyen JW. The fear-avoidance model of musculoskeletal pain: current state of scientific evidence. JBehav Med. 2007;30:77-94. https://doi.org/10.1007/s10865-006-9085-0

16. Leeuw M, Goossens ME, van Breukelen GJ, Boersma K, Vlaeyen JW. Measuring perceived harmfulness of physical activities in patients with chronic low back pain: the Photograph Series of Daily Activities-short electronic version. JPain. 2007;8:840-849. https://doi.org/10.1016/ j.jpain.2007.05.013

17. Leeuw M, Goossens ME, van Breukelen GJ, et al. Exposure in vivo versus operant graded activity in chronic low back pain patients: results of a randomized controlled trial. Pain. 2008;138:192207. https://doi.org/10.1016/.pain.2007.12.009

18. Lethem J, Slade PD, Troup JD, Bentley G. Outline of a fear-avoidance model of exaggerated pain perception-I. Behav Res Ther. 1983;21:401-408. https://doi.org/10.1016/0005-7967(83)90009-8

19. Lundberg M, Grimby-Ekman A, Verbunt J, Simmonds MJ. Pain-related fear: a critical review of the related measures. Pain Res Treat. 2011;2011:494196. https://doi.org/10.1155/ 2011/494196

20. Mackelvie CP, Seenan C, Ryan CG. Physiotherapist-led exercise classes for low back pain show changes in disability and fear of movement: a service evaluation. Pain Rehabil. 2016;41:31-36.

21. Magalhães MO, Muzi LH, Comachio J, et al. The short-term effects of graded activity versus physiotherapy in patients with chronic low back pain: a randomized controlled trial. Man Ther. 2015;20:603-609. https://doi.org/10.1016/ j.math.2015.02.004

22. Miller RP, Kori SH, Todd DD. The Tampa Scale: a measure of kinesiophobia [abstract]. Clin J Pain. 1991;7:51-52.

23. Mokkink LB, Terwee CB, Patrick DL, et al. The COSMIN checklist for assessing the methodological quality of studies on measurement properties of health status measurement instruments: an international Delphi study. Qual Life Res. 2010;19:539-549. https://doi.org/10.1007/s11136-010-9606-8

24. Mokkink LB, Terwee CB, Patrick DL, et al. COSMIN Checklist Manual. Amsterdam, the Netherlands: EMGO Institute for Health and Care Research; 2012.

25. Monticone M, Ambrosini E, Rocca B, Foti C, Ferrante S. Responsiveness of the Tampa Scale of Kinesiophobia in Italian subjects with chronic low back pain undergoing motor and cognitive rehabilitation. Eur Spine J. 2016;25:2882-2888. https://doi.org/10.1007/s00586-016-4682-2

26. Nusbaum L, Natour J, Ferraz MB, Goldenberg J. Translation, adaptation and validation of the Roland-Morris questionnaire - Brazil Roland-Morris. Braz J Med Biol Res. 2001;34:203-210. https://doi.org/10.1590/

\section{S0100-879X2001000200007}

27. Pincus T, Burton AK, Vogel S, Field AP. A systematic review of psychological factors as predictors of chronicity/disability in prospective cohorts of low back pain. Spine (Phila Pa 1976). 2002;27:E109-E120.

28. Pincus T, Smeets RJ, Simmonds MJ, Sullivan MJ. The fear avoidance model disentangled: improving the clinical utility of the fear avoidance model. Clin JPain. 2010;26:739-746. https://doi. org/10.1097/AJP.0b013e3181f15d45

29. Portney LG, Watkins MP. Foundations of Clinical Research: Applications to Practice. 2nd ed. Upper Saddle River, NJ: Prentice Hall Health; 2000.

30. Rainville J, Smeets RJ, Bendix T, Tveito TH, Poiraudeau S, Indahl AJ. Fear-avoidance beliefs and pain avoidance in low back pain-translating research into clinical practice. Spine J. 2011;11:895903. https://doi.org/10.1016/j.spinee.2011.08.006

31. Roland M, Morris R. A study of the natural history of back pain. Part l: development of a reliable and sensitive measure of disability in low-back pain. Spine (Phila Pa 1976). 1983;8:141-144.

32. Siqueira FB, Teixeira-Salmela LF, Magalhães LC. Análise das propriedades psicométricas da versão brasileira da escala tampa de cinesiofobia. Acta Ortop Bras. 2007;15:19-24. https://doi.org/10.1590/ S1413-78522007000100004

33. Staerkle R, Mannion AF, Elfering A, et al. Longitudinal validation of the Fear-Avoidance Beliefs Questionnaire (FABQ) in a Swiss-German sample of low back pain patients. Eur Spine J. 2004;13:332-340. https://doi.org/10.1007/ s00586-003-0663-3

34. Swinkels-Meewisse EJ, Swinkels RA, Verbeek AL, Vlaeyen JW, Oostendorp RA. Psychometric properties of the Tampa Scale for Kinesiophobia and the fear-avoidance beliefs questionnaire in acute low back pain. Man Ther. 2003;8:29-36. https://doi.org/10.1054/math.2002.0484

35. Swinkels-Meewisse IE, Roelofs J, Schouten EG, Verbeek AL, Oostendorp RA, Vlaeyen JW. Fear of movement/(re)injury predicting chronic disabling low back pain: a prospective inception cohort study. Spine (Phila Pa 1976). 2006;31:658-664. https://doi.org/10.1097/01. brs.0000203709.65384.9d

36. Terwee CB, Bot SD, de Boer MR, et al. Quality criteria were proposed for measurement properties of health status questionnaires. $\mathbf{J}$ Clin Epidemiol. 2007;60:34-42. https://doi. org/10.1016/j.jclinepi.2006.03.012

37. Verbunt JA, Nijhuis A, Vikström M, et al. The psychometric characteristics of an assessment instrument for perceived harmfulness in adolescents with musculoskeletal pain (PHODAyouth). Eur J Pain. 2015;19:695-705. https://doi. org/10.1002/ejp.592

38. Vlaeyen JW, Linton SJ. Fear-avoidance and its consequences in chronic musculoskeletal pain: a state of the art. Pain. 2000;85:317-332. https:// doi.org/10.1016/S0304-3959(99)00242-0

39. Vlaeyen JW, Morley S. Cognitive-behavioral 
treatments for chronic pain: what works for whom? Clin J Pain. 2005;21:1-8.

40. Waddell G, Newton M, Henderson I, Somerville D, Main CJ. A Fear-Avoidance Beliefs Questionnaire (FABQ) and the role of fearavoidance beliefs in chronic low back pain and disability. Pain. 1993;52:157-168. https://doi. org/10.1016/0304-3959(93)90127-B

41. Wertli MM, Eugster R, Held U, Steurer J, Kofmehl $\mathrm{R}$, Weiser S. Catastrophizing-a prognostic factor for outcome in patients with low back pain: a systematic review. Spine J. 2014;14:2639-2657. https://doi.org/10.1016/j.spinee.2014.03.003

42. Wertli MM, Rasmussen-Barr E, Weiser $\mathrm{S}$, Bachmann LM, Brunner F. The role of fear avoidance beliefs as a prognostic factor for outcome in patients with nonspecific low back pain: a systematic review. Spine J. 2014;14:816-836.e4. https://doi.org/10.1016/j. spinee.2013.09.036
43. Wideman TH, Asmundson GG, Smeets RJ, et al. Rethinking the fear avoidance model: toward a multidimensional framework of pain-related disability. Pain. 2013;154:2262-2265. https://doi. org/10.1016/j.pain.2013.06.005

\section{EARN CEUs With JOSPT's Read for Credit Program}

JOSPT's Read for Credit (RFC) program invites readers to study and analyze selected JOSPT articles and successfully complete online exams about them for continuing education credit. To participate in the program:

1. Go to www.jospt.org and click on Read for Credit in the top blue navigation bar that runs throughout the site.

2. Log in to read and study an article and to pay for the exam by credit card.

3. When ready, click Take Exam to answer the exam questions for that article.

4. Evaluate the RFC experience and receive a personalized certificate of continuing education credits.

The RFC program offers you 2 opportunities to pass the exam. You may review all of your answers-including your answers to the questions you missed. You receive $\mathbf{0 . 2}$ CEUs, or 2 contact hours, for each exam passed.

JOSPT s website maintains a history of the exams you have taken and the credits and certificates you have been awarded in My CEUs and Your Exam Activity, located in the right rail of the Read for Credit page listing available exams. 
This article has been cited by:

1. Crystian B Oliveira, Rafael Z Pinto. 2021. Clinimetrics: Photograph Series of Daily Activities - Short Electronic Version (PHODA-SeV). Journal of Physiotherapy 67:3, 222. [Crossref]

2. Giulia M. D. Araujo, Rafael Z. Pinto, Bruna R. Azevedo, Fernanda G. Silva, Tatiana M. Damato, Guilherme D. Grande, Diego G. D. Christofaro, Crystian B. Oliveira. 2021. Measurement Properties of the Sedentary Behavior Questionnaire in Patients with Chronic Nonspecific Low Back Pain. PM\& R 13:3, 250-257. [Crossref]

3. Letícia Bojikian Calixtre, Carlos Luques Fonseca, Bruno Leonardo da Silva Gruninger, Danilo Harudy Kamonseki. 2020. Psychometric properties of the Brazilian version of the Bournemouth questionnaire for low back pain: validity and reliability. Brazilian Journal of Physical Therapy 390. . [Crossref]

4. Érica Brandão de Moraes, Francisco Farias Martins Júnior, Cibele Andrucioli de Mattos-Pimenta. 2020. In vivo exposure for fear of pain and avoidance of movement in low back pain. Revista Brasileira de Enfermagem 73:5. . [Crossref]

5. Thomas Matheve, Liesbet De Baets, Katleen Bogaerts, Annick Timmermans. 2019. Lumbar range of motion in chronic low back pain is predicted by task-specific, but not by general measures of pain-related fear. European Journal of Pain 23:6, 1171-1184. [Crossref]

6. Samantha J. Demarchi, Crystian B. Oliveira, Marcia R. Franco, Priscila K. Morelhão, Thalysi M. Hisamatsu, Fernanda G. Silva, Tatiana M. Damato, Rafael Z. Pinto. 2019. Association of perceived physical overload at work with pain and disability in patients with chronic non-specific low back pain: a 6-month longitudinal study. European Spine Journal 28:7, 1586-1593. [Crossref]

7. Aoife Leahy, Mary O'Keeffe, Katie Robinson, Kieran O'Sullivan. 2019. The beliefs of healthcare students about the harmfulness of daily activities for their back: a cross-sectional study. European Journal of Physiotherapy 2014, 1-7. [Crossref]

8. Jason M. Beneciuk, Lindsay A. Ballengee, Steven Z. George. 2019. Treatment monitoring as a component of psychologically informed physical therapy: A case series of patients at high risk for persistent low back pain related disability. Musculoskeletal Science and Practice 41, 36-42. [Crossref] 